\title{
Baseline and stress-induced levels of corticosterone in male and female Afrotropical and European temperate stonechats during breeding
}

Beate Apfelbeck ${ }^{1,2^{*}}$, Barbara Helm ${ }^{1}$, Juan Carlos Illera ${ }^{4}$, Kim G. Mortega ${ }^{1,3^{*}}$, Patrick Smiddy ${ }^{5}$ and Neil P. Evans ${ }^{1}$

\begin{abstract}
Background: Latitudinal variation in avian life histories falls along a slow-fast pace of life continuum: tropical species produce small clutches, but have a high survival probability, while in temperate species the opposite pattern is found. This study investigated whether differential investment into reproduction and survival of tropical and temperate species is paralleled by differences in the secretion of the vertebrate hormone corticosterone (CORT). Depending on circulating concentrations, CORT can both act as a metabolic (low to medium levels) and a stress hormone (high levels) and, thereby, influence reproductive decisions. Baseline and stress-induced CORT was measured across sequential stages of the breeding season in males and females of closely related taxa of stonechats (Saxicola spp) from a wide distribution area. We compared stonechats from 13 sites, representing Canary Islands, European temperate and East African tropical areas. Stonechats are highly seasonal breeders at all these sites, but vary between tropical and temperate regions with regard to reproductive investment and presumably also survival.
\end{abstract}

Results: In accordance with life-history theory, during parental stages, post-capture (baseline) CORT was overall lower in tropical than in temperate stonechats. However, during mating stages, tropical males had elevated post-capture (baseline) CORT concentrations, which did not differ from those of temperate males. Female and male mates of a pair showed correlated levels of post-capture CORT when sampled after simulated territorial intrusions. In contrast to the hypothesis that species with low reproduction and high annual survival should be more risk-sensitive, tropical stonechats had lower stress-induced CORT concentrations than temperate stonechats. We also found relatively high post-capture (baseline) and stress-induced CORT concentrations, in slow-paced Canary Islands stonechats.

Conclusions: Our data support and refine the view that baseline CORT facilitates energetically demanding activities in males and females and reflects investment into reproduction. Low parental workload was associated with lower post-capture (baseline) CORT as expected for a slow pace of life in tropical species. On a finer resolution, however, this tropical-temperate contrast did not generally hold. Post-capture (baseline) CORT was higher during mating stages in particular in tropical males, possibly to support the energetic needs of mate-guarding. Counter to predictions based on life history theory, our data do not confirm the hypothesis that long-lived tropical populations have higher stress-induced CORT concentrations than short-lived temperate populations. Instead, in the predator-rich tropical environments of African stonechats, a dampened stress response during parental stages may increase survival probabilities of young. Overall our data further support an association between life history and baseline CORT, but challenge the role of stress-induced CORT as a mediator of tropical-temperate variation in life history.

Keywords: Life history, Corticosterone, Tropical-temperate, Simulated territorial intrusion (STI), Seasonal

\footnotetext{
*Correspondence: bea.apfelbeck@gmx.de

'Institute of Biodiversity, Animal Health and Comparative Medicine, University

of Glasgow, Glasgow, Scotland G12 8QQ, UK

Full list of author information is available at the end of the article
} 


\section{Background}

Environmental variation across latitudinal gradients has led to consistent differences in vertebrate life histories [1]. This is especially well studied in birds where tropical birds produce smaller clutches of offspring [2] and have lower basal metabolic rates $[3,4]$, but live longer $[5,6]$ than temperate birds. Such differences in pace of life between tropical and temperate birds [7] suggest a trade-off between current reproduction and longevity. Clutch size manipulation experiments in temperate birds have shown that reproduction in birds is indeed costly because enlarged broods can reduce future reproductive success and survival of parents (e.g. [8-12]). Costs of reproduction may arise because limited resources, for example energy, nutrients or time, cannot be allocated simultaneously to competing traits [13] and because of functional relationships between physiological systems $[7,14]$. Therefore, it has been suggested that the evolution of life history traits is not only limited by environmental factors, but by physiological control systems that integrate environmental information [7]. In particular, endocrine control mechanisms may play an important role as mediators of life history trade-offs [7, 15-18].

The neuroendocrine stress axis represents a key interface between the external and internal environments of animals. Vertebrates respond to diverse challenges by activation of the hypothalamic-pituitary-adrenal (HPA) axis, which is highly conserved across vertebrate species. The HPA axis coordinates the physiological and behavioural responses to both energetically demanding situations and potentially life-threatening events [19-21]. The major effectors of the HPA axis are the glucocorticoids - the most important of which, in birds, is corticosterone (CORT, or cortisol in most mammals and fishes). CORT operates at distinct concentrations through binding to receptors of different affinity [19]. Baseline concentrations are thought to mediate the energetic needs of daily life and may be elevated during periods of high metabolic activity. In contrast, high concentrations occur when an individual is under stress and are thought to promote life-saving activities [21].

Baseline CORT concentrations are commonly upregulated during breeding (e.g. [22, 23], but see [24, 25] for examples where baseline CORT does not change during reproduction). Both experimental and correlational evidence suggests that elevated baseline CORT concentrations may prepare both sexes for increased energetic needs during the mating and parental phases [26-33]. Furthermore, parents with large broods and parents that feed their nestlings at high rates have higher baseline CORT concentrations than those with small broods and low feeding rates [28]. Thus, elevated baseline CORT concentrations during breeding can correlate with individual reproductive success [34-37]. On the other hand, elevated CORT levels after the breeding season have been shown to be negatively correlated with survival [38].

In response to unpredictable, life-threatening stressors, CORT concentrations can reach very high, "stress-induced" concentrations that may trigger an "emergency life history stage" [21]. This stage helps the individual to survive through physiological changes and by redirecting behaviour towards life-saving activities [21], although evidence for survival benefits is so far based on few studies $[39,40]$. Support for this idea comes from observations that effects of stress-induced CORT are influenced by individual body condition. For example, experimentally increased high stress-induced CORT concentrations during periods of harsh weather can induce parents to leave their breeding sites temporarily or to abandon completely their current breeding attempt, especially if they have low body condition [41-43].

Thus, glucocorticoids are thought to mediate the trade-off between reproduction and survival by either promoting high reproductive output at the expense of future survival (elevated baseline concentrations) or by favouring immediate survival at the expense of current reproduction (high stress-induced concentrations). These effects of modulated levels of baseline and stressinduced CORT on reproductive success greatly depend on context, such as life history stage, prevailing environmental conditions, and a species' life history (reviewed in $[39,40,44])$. For example, in female tree swallows (Tachycineta bicolor), baseline CORT concentrations are negatively correlated with clutch mass and number of offspring when CORT is measured early during the incubation stage, but positively when CORT is measured during the nestling stage [34]. Similarly, the number of fledglings in house sparrows (Passer domesticus) were predicted by low pre-breeding, but high baseline CORT concentrations when feeding young [35]. The stressinduced CORT response can also be modulated during breeding, according to the value of a brood ("brood value hypothesis", [42-44]). For example, house sparrows show a dampened CORT stress response when the value of their brood is experimentally increased [45], but an increased CORT stress response when the value of their brood is decreased [46]. An example for the importance of both, life history and environmental conditions, is provided by red crossbills (Loxia curvirostra), an opportunistic breeder that can breed both during summer and winter. In this species, individuals show a reduced stress response when in high breeding condition during winter, but not when breeding in summer [45]. Effects of CORT on adult survival may also depend on environmental context. For example, the stress response of non-breeding American redstarts (Setophaga ruticilla) predicts their return probability to their breeding sites when they overwinter in low quality scrub habitat, but 
not when they overwinter in high quality mangrove habitat [46].

Hence, despite general evidence that CORT mediates the trade-off between reproduction and survival, relationships between CORT and fitness are diverse, and a better understanding of the context that shapes them is required. There is clear need for clarifying studies that investigate CORT across a wide range of environments and life-history parameters. A particularly promising avenue for such research are the consistent differences in life histories between large-clutched, short-lived temperate and small-clutched, long-lived tropical birds $[2,5,6]$. Assuming that CORT mediates the underlying trade-offs, clear hypotheses for comparisons between temperate and tropical birds have been posited [17].

Short-lived, temperate species with a low probability of future breeding attempts should have higher baseline CORT concentrations, but lower stress-induced CORT concentrations than long-lived, tropical species, which have a higher probability of survival and that thus may have further breeding opportunities [17, 47]. In support of this hypothesis, in a comparative study between neotropical and North American temperate songbirds, Hau et al.[17] found that neotropical species indeed had lower baseline CORT concentrations than North American temperate birds and that stress-induced CORT concentrations positively co-varied with annual adult survival rate [17]. However, no detailed study so far has compared CORT concentrations of males and females of closely related species during their breeding activities at tropical and temperate latitudes [31].

Our study system, the common stonechat species complex (Saxicola torquata), has an extensive breeding range from Siberia to Southern Africa [48] and has played a major role in the development of the pace of life theory [7]. Stonechats show a robust latitudinal cline in metabolic rate, with genetically inherited, higher metabolic rates in higher-latitude populations $[4,49,50]$. Stonechats are socially monogamous seasonal breeders and defend a breeding territory regardless of latitude [48], but they also display a clear latitudinal cline in life history. Common garden experiments have shown that tropical stonechats have a genetically fixed smaller clutch size [51]. In the wild, tropical stonechats generally lay a single clutch, while temperate stonechats produce up to three consecutive clutches [48]. Tropical stonechats are residents or occasional altitudinal migrants and stay with the same partner year round, while migratory disposition of European stonechats varies from resident to migratory [48]. Local survival of tropical stonechats seems to be much higher than that of temperate stonechats: In previous studies the local apparent annual survival of stonechats in East Africa varied between $65-85 \%$ [52], while in a European population it was only $29-45 \%[53,54]$. Thus, stonechats are an ideal model system to study the endocrine mechanisms underlying differences in pace of life in a phylogenetically controlled setting [18].

Captivity studies under controlled conditions have strongly suggested associated clines in basal and stressinduced CORT and pace of life of different stonechat populations: fast-lived populations had higher baseline, and surprisingly, also higher stress-induced CORT than slow-lived populations [50]. However, it is unclear to which extent patterns would hold in actively breeding birds under natural conditions. Under field conditions, CORT patterns have been described for tropical stonechats $[31,55]$, but detailed data are in particular lacking for higher latitude populations. Furthermore, to address the context-dependence of CORT modulation, fine resolution information on sequential breeding stages is required [31]. Lastly, because earlier data were derived from very few populations, the generality of these patterns still needs to be tested.

To robustly test for hormonal differences with respect to pace of life, in this study we focused on the breeding season, when trade-offs occur, and collected comparative data from a large number of free-living stonechats. We compared baseline and stress-induced CORT concentrations of tropical stonechats from East Africa and temperate stonechats from Europe. We also included data from an island population from Fuerteventura (Canary Islands) that breeds at latitudes intermediate to mainland European and East African populations (although closer to mainland Europe than East Africa, $[56,57])$ and that has a slow pace of life. Canary Islands stonechats (Saxicola dacotiae) are endemics of the semiarid island of Fuerteventura and have high local apparent annual survival (81\%, [57]). Similar to East African stonechats, they breed during the rainy season, but may skip reproduction in very dry years. Clutch size (3-4 eggs) and the number of breeding attempts (0-2) depend on the amount of rain during the breeding season [56]. This present study is complementary to our recently published twin study on testosterone, another hormone implicated in life history trade-offs [18]. Samples used to determine the hormones in the two studies were obtained from the same populations and the same individual stonechats to a great extent.

Based on life history theory we hypothesized that CORT during breeding would differ between tropical, temperate and island stonechats according to their pace of life. Because tropical stonechats have a slower pace of life and are less fecund we predicted that they have lower baseline CORT concentrations than European stonechats. However, because of the short and highly synchronous breeding seasons in these tropical birds, male African stonechats could have elevated baseline 
CORT concentrations that are comparable to those of

European males during the mating stages [18, 31].

With respect to breeding stage we expected similar within-species patterns in temperate and tropical stonechats. In females, we expected higher baseline CORT when incubating and feeding nestlings and fledglings than during mating in accordance with the potential role of baseline CORT as a mediator of parental investment. In males, we expected elevated CORT during the mating stages because of the short breeding seasons in both tropical and temperate stonechats $[18,31]$. In addition, we expected higher baseline CORT when feeding young than during the incubation stage.

For stress-induced CORT, because the annual mortality of African stonechats is lower, we predicted that they should invest more into self-maintenance and be more risk sensitive and, therefore, have higher concentrations than European stonechats. Due to their slow pace of life, we expected that stonechats on Fuerteventura would have similar baseline and stress-induced CORT concentrations as East African stonechats.

\section{Methods}

\section{Species and populations}

Baseline and stress-induced CORT blood samples were collected from phylogenetically related stonechat taxa during their respective breeding seasons in tropical East Africa (Saxicola torquata axillaris, 8 populations, 112 males, 66 females, latitudes $0^{\circ}-4^{\circ} \mathrm{S}$, altitudinal range: 1376-2500 m asl, sampled from 2012-2013; collectively referred to as African stonechats because of their breeding range within the tropics, i.e. within $23.5^{\circ}$ of latitude), Europe (Saxicola torquata rubicola, 4 populations, 59 males, 30 females, latitudes $37^{\circ}-51^{\circ} \mathrm{N}$, altitudinal range: $15-1350 \mathrm{~m}$ asl, sampled in 2013; collectively referred to as European stonechats), and Fuerteventura (Saxicola dacotiae, 13 males, 7 females, latitude $28^{\circ} \mathrm{N}$, altitudinal range $57-359 \mathrm{~m}$ asl, sampled in 2013; referred to as Canary Islands stonechats). For detailed geographical locations and life history information see Additional file 1: Table S1. Stonechats from all East African populations lay a small clutch with on average three eggs, but breed at different times of the year corresponding to one of the two major rainy seasons. Southern populations breed from October to December [58], while Northern populations breed from March to July [59]. European stonechats (Saxicola torquata) breed from March to July [48], whereas Canary Islands stonechats breed according to rainfall from December/January to March [56].

We collected data on breeding biology, nestlings, and adults by observations and by capture. Breeding stage was categorized as pre-nesting, nest-building, egg-laying, incubation, nestlings and fledglings. Of these, combinations of pre-nesting, nest-building and egg-laying are collectively referred to as mating stage. Stages were determined by careful observation of pairs before capture (e.g. singing activity, nest-building activity by female, feeding activity of nestlings, presence of fledglings), and by assessing the presence or absence of a brood patch in captured females. For located nests, we recorded the number of eggs or nestlings and checked the nest again after a few days. We recorded geographical location and altitude using a GPS device. All individuals were measured (weight, tarsus and wing length), checked for moult, ringed with a numbered aluminium ring and a combination of three colour rings and were then released back into their territories. We determined the age of all individuals caught as either yearling ( $<2$ years) or adult ( $\geq 2$ years) based on feather moult pattern of the wings $[60,61]$.

\section{Capture methods}

Stonechats were caught between $0700 \mathrm{~h}$ and $1800 \mathrm{~h}$ with baited clap net traps but also in some cases additionally lured by a mounted decoy and playback (simulated territorial intrusion (STI)). STIs have been previously used in stonechat studies [62-67]. Traps were observed continuously and upon capture birds were immediately removed from the traps. For STIs, one trap was fixed to the side of the decoy and several additional traps were baited and placed on the ground. According to an earlier study on African stonechats, the differences in trapping method affected CORT concentrations only for early breeding stages [31]. To further assess whether CORT is modulated in response to simulated territorial intrusions in stonechats, in Africa some individuals were caught using STI (time to catch (mean \pm SD): $27 \pm 22 \mathrm{~min}$, Table 1), while others were caught with baited clap net traps only (time to catch (mean $\pm \mathrm{SD}$ ): $46 \pm 36 \mathrm{~min}$, Table 1). In Europe, all males were caught during simulated territorial intrusions (time to catch (mean $\pm \mathrm{SD}$ ): $36 \pm 30 \mathrm{~min}$, Table 1 ). To elicit a territorial response a remote-controlled loudspeaker (Foxpro Scorpion, digital game caller, FOXPRO Inc. Lewistown, USA) was put underneath a decoy to play back the territorial song of a potential rival at a sound pressure level of $65 \mathrm{~dB}$ SPL at $1 \mathrm{~m}$ (as measured with a CEL 573.B1 Sound Level Analyser). In Europe we used playbacks downloaded from the British library or from http://www.xeno-canto.org/. In Africa, we used playback songs, which were recorded from the same population. All females were caught with baited clap net traps (time to catch (mean $\pm \mathrm{SD}$ ): Africa: $38 \pm 30$ min, Europe: $54 \pm 39$ min, Table 1), but were in some cases caught during a catching event of their mates and, hence, sometimes exposed to STIs before capture. Male and female Canary Islands stonechats were caught with baited clap net traps without playback (time to catch (mean \pm SD): $21 \pm 23$ min, Table 1). For a summary of the different capture 
Table 1 Overview of sample sizes by sex, capture method, and breeding stage during which individuals were caught in the different breeding regions (Africa, Europe, Canary Islands)

\begin{tabular}{|c|c|c|c|c|c|c|c|}
\hline \multirow[t]{2}{*}{ Region, sex } & \multirow[t]{2}{*}{ Capture method } & \multicolumn{3}{|l|}{ Mating } & \multirow[t]{2}{*}{ Incubation } & \multicolumn{2}{|l|}{ Young } \\
\hline & & Pre-nesting & Egg-laying & Nest-building & & Nestlings & Fledglings \\
\hline \multirow[t]{2}{*}{ Africa, males } & baited clap net traps & 0 & 0 & 3 & 10 & 12 & 15 \\
\hline & STI & 18 & 4 & 9 & 16 & 11 & 14 \\
\hline Africa, females & baited clap net traps & 1 & 1 & 6 & 23 & 18 & 17 \\
\hline Europe, males & STI & NA & 9 & 2 & 31 & 4 & 10 \\
\hline Europe, females & baited clap net traps & NA & 10 & 3 & 7 & 6 & 4 \\
\hline Canary Islands, males & baited clap net traps & NA & NA & NA & 7 & 1 & 5 \\
\hline Canary Islands, females & baited clap net traps & NA & NA & NA & 3 & 1 & 3 \\
\hline
\end{tabular}

NA indicates non-available data

methods that were used in the different breeding regions and in the two sexes see Table 1.

\section{Plasma separation and hormone analysis}

To measure baseline concentrations of CORT an initial blood sample $(\sim 120 \mu \mathrm{l})$ was taken within $3 \mathrm{~min}$ of capture (mean \pm SD: Africa males: $120 \pm 32 \mathrm{~s}$, Africa females: $124 \pm 36 \mathrm{~s}$; Europe males: $119 \pm 40 \mathrm{~s}$, Europe females: $111 \pm 33 \mathrm{~s}$, Canary Islands males: $105 \pm 34 \mathrm{~s}$, Canary Islands females: $107 \pm 35 \mathrm{~s}$; [68]) by venipuncture of the wing vein or (less often) with a syringe from the jugular vein and collected into heparinized capillaries. CORT concentrations sampled from the wing or jugular vein have been shown to be similar in male song sparrows (Melospiza melodia) [69]. To measure stress-induced CORT, individuals were kept in an opaque cloth bag and a second blood sample $(\sim 50 \mu \mathrm{l})$ was taken $30 \mathrm{~min}$ after capture. In both instances, plasma was immediately separated by centrifugation with a Compur Minicentrifuge (Bayer Diagnostics) or a Spectrafuge Mini Laboratory Centrifuge (Labnet International, Inc.). The amount of plasma was measured with a Hamilton syringe and stored in $500 \mu \mathrm{l}$ pure ethanol [70]. After the end of each field season ( $\leq 4$ months) samples were stored at $-80^{\circ} \mathrm{C}$. CORT concentrations were quantified using an enzyme immunoassay kit (EIA, Cayman \#500655) according to the manufacturer's instructions. The kit has been previously validated in another songbird, the dark-eyed junco (Junco hyemalis, [71]) and we further established parallelism between a standard curve based upon reference standards provided by the kit and stonechat plasma dilution curves $(\mathrm{x} 1, \mathrm{x} 2$, $\mathrm{x} 4, \mathrm{x} 8, \mathrm{x} 16)$ using stress-induced samples from two individuals. Briefly, $1000 \mu \mathrm{l} \mathrm{dH_{2 } 0}$ and $10 \mu \mathrm{l}$ of tritiated CORT $(\sim 8000 \mathrm{cpm})$ were added to each sample, and then samples were allowed to equilibrate overnight. Samples were extracted twice with 4 and $2 \mathrm{ml}$ of diethyl ether, respectively, dried with $\mathrm{N}_{2}$ and reconstituted with $300 \mu \mathrm{l}$ assay buffer. Baseline samples were diluted 1:4 and stress-induced samples 1:10 prior to plating in duplicate. A pool of zebra finch plasma was extracted together with the samples and included in each plate undiluted and in a 1:4 dilution to assess intra- and interassay variation. The concentration of CORT in plasma samples was calculated by using a standard curve run in duplicate on each plate and corrected for incomplete recoveries (average extraction efficiency: $71 \pm 7 \%$ ). Samples were quantified in 18 assays, each containing samples from African and European populations with baseline and stress-induced samples from the same individual on the same plate. Inter-assay variation ranged from $13.6 \%$ (undiluted internal control, $n=18$ ) to $17.9 \%$ (1:4 diluted internal control, $n=18)$ and intraassay variation ranged from 1.6 to $17.5 \%$ (average: $10.1 \%$, $n=18)$.

\section{Statistical analysis}

Data were analysed within the $R$ environment ( $R$ version 3.2.2, [72]) and the packages arm [73], JAGS [74] and runjags [75]. Bayesian linear mixed models (see below for more information) were used to determine whether variation in CORT was related to breeding region (tropical Africa, temperate Europe, Canary Islands), breeding stage or the interaction between breeding region and breeding stage. Population identity within a breeding region was included as a random intercept.

Baseline and stress-induced CORT concentrations were natural log-transformed prior to analysis and predictor covariates (scaled mass index, time of day, playback duration, handling time) were centred to a mean of zero. Handling time refers to the time elapsed between capture and the initial baseline blood sample. As handling time was similar for all stress-induced samples ( 30 min after capture) it was not included in the analysis of stress-induced CORT concentrations. Predictor covariates and their interactions were removed from the models when they did not explain a significant amount of variation in the data (i.e. credible intervals included zero). Predictor variables that were part of the experimental set-up / hypothesis (breeding region, breeding 
stage) were always retained in the models. CORT data were analysed over several subsets. Data of males and females were analysed separately because of their different reproductive roles and because capture methods differed (males: STI or baited traps; females: baited traps, Table 1). In males, we checked for effects of capture method and breeding stage, using African stonechats which had the greatest range of capture methods and breeding stages (Table 1). We then compared males of African and European populations, and African and Canary Island stonechats, respectively, using subsets with matched capture methods and breeding stages (Table 1). In females, we first compared African and European populations, which had the greatest range of breeding stages, and then we compared Canary Island stonechats to both populations (Table 1). Finally, we also analysed the relationship of CORT between mates that were sampled under comparable conditions, i.e. during the same catching event.

\section{CORT males}

Baseline CORT concentrations were analysed for differences between capture method (STI, control) and breeding stage in African males. Breeding stage was included as a factor with four levels: mating (comprising pre-nesting, nest-building and egg-laying), incubation, nestlings and fledglings (Table 1). Because of low sample sizes during the mating stage in control birds $(n=3)$ we did not include a capture method"breeding stage interaction in the model. In a next step, we analysed differences in CORT concentrations between African and European males. Because capture method had a significant influence on CORT in African males, and European males were only caught using STIs (Table 1), only African males that had been caught with STI were included in the comparison between African and European males. In this comparison, breeding stage was included as a factor with three levels: mating (nest-building and egg-laying), incubation and young (nestlings and fledglings, Table 1). In Europe, no males had been caught during pre-nesting (Table 1) and we, therefore, restricted the mating stage to nest-building and egg-laying, resulting in smaller sample sizes for African males compared to the Africa only analysis. Effects of breeding region, breeding stage and any interaction between breeding region and breeding stage were investigated for baseline and stress-induced CORT. Further, we tested whether stress-induced CORT was dependent on baseline CORT and whether these relationships differed between breeding regions. Finally, males of the Canary Islands stonechat and males from Africa that were caught without STI were compared using linear models (no random intercept). European males were not included as they had been caught exclusively with STIs. Samples were restricted to incubation and feeding of young stages, and breeding stage was not included as a factor (Table 1). Because of the positive effect of STIs on CORT concentrations in males, we refer to CORT concentrations directly after capture as post-capture CORT instead of baseline CORT concentrations.

\section{CORT females}

Baseline and stress-induced CORT concentrations were tested for differences between European and African females. We included in the model the factors breeding region, breeding stage, and the interaction between breeding region and breeding stage. Breeding stage was defined as a factor with the three levels mating (including nest-building and egg-laying), incubation and young (including nestling and fledgling stages, Table 1). Females of the Canary Islands stonechat were included in linear models (no random intercept) that were restricted to the incubation and feeding of young stages. Breeding stage was not included as a factor because of small sample sizes for Canary Islands stonechats for the different breeding stages (Table 1). In a last step, CORT concentrations of females were tested for correlations with CORT concentrations of their male mates using linear models. In these models, data from all populations were used. The analysis was restricted to pairs that were caught during a single catching event which in some cases involved STI $(n=61)$.

Body condition for African, European and Canary Islands stonechats was estimated separately for males and females using each individual's body mass and tarsus length in a scaled mass index (SMI, following Peig and Green (2010) [76]). The SMI analysis standardizes body mass at a fixed value of a linear body measurement based on the scaling relationship between mass and length, in our case tarsus length. This value is derived from empirical values, in our case on data from 627 individuals (Africa: males $n=122$, females $n=85$, Europe: males $n=193$, females $n=108$, Canary Islands: males $n=82$, females $n=37$ ) including individuals for which we had not collected CORT samples. The scaling exponent $\left(\mathrm{b}_{\text {sma }}\right)$ was estimated through standard major axis regression of body mass against tarsus length on a natural $\log$ scale. We determined $b_{\text {sma }}$ and mean tarsus length required for the calculation of the SMI for each sex and breeding region separately. In European and Canary Islands stonechats the $b_{\text {sma }}$ and mean tarsus length calculations included also data from long-term ringing data sets.

We chose a Bayesian approach to draw inferences from the models because frequentist methods do not allow calculating accurate degrees of freedom in mixed model analysis [77]. Bayesian statistics estimate probability distributions of the parameters in the model (i.e. posterior distributions) given the data and prior knowledge 
about the distribution of the data (specified as priors) [78]. Model parameters were estimated as the mean of their posterior distributions, and the $2.5 \%$ and $97.5 \%$ credible intervals. Minimally informative priors for both mean (dnorm $\left.\left(0,10^{\wedge-6}\right)\right)$ and variance (dgamma $\left.(0.001,0.001)\right)$ parameters were used, i.e. we assumed no prior knowledge about the factors in our models. Marcov-Chain Monte-Carlo (MCMC) simulations were checked for convergence of chains using trace plots and psrf values [79]. Effective sample sizes were $>15000$ in all cases. Model residuals were graphically checked for violations of model assumptions (normality, heteroscedasticity, autocorrelations) [78]. Data are presented as backtransformed means and their 95\% Bayesian credible intervals in figures and as the difference and 95\% Bayesian credible interval (in squared brackets) from the mean intercept (on a natural log scale) in tables. Bayesian statistics do not produce test statistics or $p$ values, however, when the Bayesian 95\% credible interval of the difference between two means does not include zero, this can be interpreted as a detectable difference and the real estimate lies with a probability of $95 \%$ within the Bayesian credible interval [80]. Similarly, when the $95 \%$ Bayesian credible interval of the slope in a regression does not include zero a meaningful relationship between the continuous predictor and the dependent variable can be assumed [78].

\section{Results}

Males: effects of capture method and breeding stage on CORT of African males

Male African stonechats that were confronted with a STI had overall higher post-capture and stress-induced CORT concentrations than males that were caught with baited traps (Table 2, Fig. 1). Considering all males, i.e. control and STI birds combined, post-capture and stress-induced CORT concentrations were higher during mating than during incubation and when feeding fledglings (Table 2, Fig. 1). During the nestling stage, CORT tended to be lower than during mating, but the credible interval of the difference between the mating and nestling stage for post-capture CORT crossed zero (Table 2). Scaled mass index, age and time of day were not correlated with post-capture and stress-induced CORT concentrations nor did handling time influence post-capture CORT concentrations (Table 2).

\section{Males: comparison of CORT and body mass index between African and European stonechats}

African and European males, which all were caught by STI, did not differ overall in their post-capture CORT concentrations, but instead, showed differences relating to breeding stage. Post-capture CORT concentrations of African males were higher during mating than during incubation or when feeding young (Table 3, Fig. 1 and 2a). In contrast, post-capture CORT concentrations of European males did not decrease with breeding stage. Consequently, European males had higher post-capture CORT concentrations than African males when feeding young (Europe"young, Table 3, Fig. 2a). Time between start of playback and capture (STI duration) was positively correlated with post-capture CORT concentrations: birds that had been exposed to playback longest had the highest post-capture CORT concentrations when captured (Table 3). Scaled mass index, age, time of day and handling time had no detectable influence on post-capture CORT concentrations (Table 3). European males had higher stress-induced CORT concentrations than African males (Table 3, Fig. 2b). Breeding stage, the interaction between breeding stage and breeding region, scaled

Table 2 CORT concentrations of male African stonechats in relation to capture method (control, STI) and breeding stage

\begin{tabular}{|c|c|c|}
\hline & Post-capture CORT & Stress-induced CORT \\
\hline & Estimates and 95\% credible intervals & Estimates and $95 \%$ credible intervals \\
\hline $\begin{array}{l}\text { Intercept: } \\
\text { Control, mating stage }\end{array}$ & $2.6[2.2,3.0]$ & $4.1[3.8,4.3]$ \\
\hline Capture method (STI, control) & $0.7[0.4,1.0]$ & $0.3[0.1,0.5]$ \\
\hline Incubation & $-0.5[-0.9,-0.04]$ & $-0.4[-0.6,-0.1]$ \\
\hline Nestlings & $-0.4[-0.8,0.06]$ & $-0.3[-0.6,-0.05]$ \\
\hline Fledglings & $-0.5[-0.9,-0.08]$ & $-0.4[-0.7,-0.2]$ \\
\hline Scaled mass index & $-0.05[-0.2,0.07]$ & $-0.05[-0.1,0.03]$ \\
\hline Age yearling & $-0.2[-0.6,0.1]$ & $-0.1[-0.3,0.1]$ \\
\hline Time of day & $0.0002[-0.0003,0.0007]$ & $-0.0002[-0.0005,0.0002]$ \\
\hline Handling time & $0.003[-0.001,0.008]$ & \\
\hline
\end{tabular}

Data shown are estimates and 95\% Bayesian credible intervals of natural log-transformed CORT concentrations. Estimates are relative to the intercept as reference level, which here is the mating stage of controls. The left column shows the post-capture and the right column stress-induced CORT, each with the corresponding Bayesian mean estimate and its' credible intervals. Estimates of the cofactors capture method and breeding stages refer to differences from the intercept estimate. When 0 (zero) is not included in the credible intervals there is a detectable effect of this parameter on the dependent variable (shown in bold) 


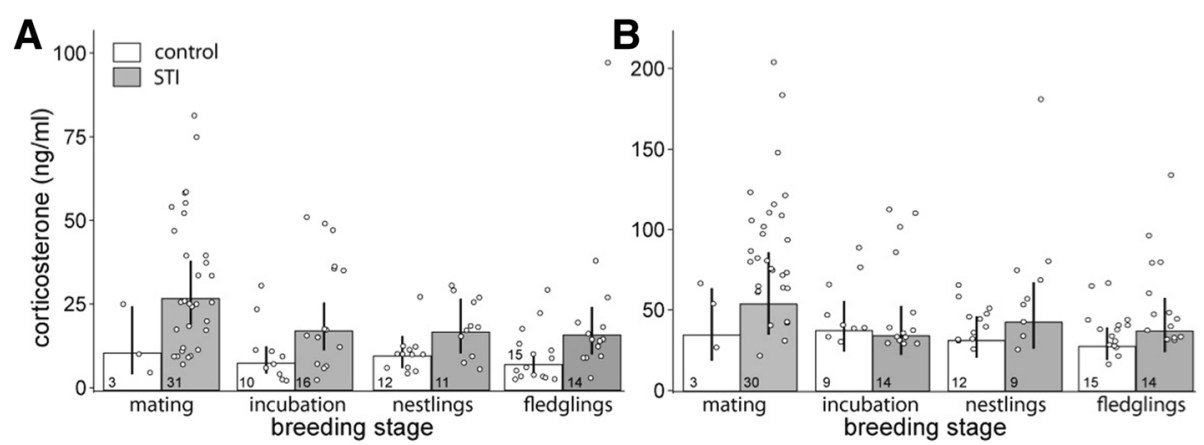

Fig. 1 Effects of capture method on (a) post-capture and (b) stress-induced CORT concentrations of African male stonechats caught during different breeding stages. Males caught in a control situation with a baited trap had lower CORT concentrations than males caught during simulated territorial intrusions (STI) with playback and decoy. Although control and STI birds are presented separately during each breeding stage, we had not included a capture method*breeding stage interaction in the model because of low sample sizes for control birds during mating. Bars and error bars represent back-transformed posterior means and their $95 \%$ Bayesian credible intervals, open dots represent data points from individuals. Different populations were included as random intercepts in the models. Sample sizes are given inside bars

mass index, age and time of day had no detectable influence on stress-induced CORT concentrations (Table 3, Fig. 2b).

Stress-induced CORT concentrations correlated positively with post-capture CORT concentrations in European, but not in African male stonechats (Africa (intercept): 3.8 [3.1, 4.4], slope all: $0.1[-0.06,0.3]$, slope Europe: 0.3 [0.07, 0.6], Fig. 3a).

Scaled mass index of African males was higher than that of European males (Africa (intercept): 16.3 [15.9, 16.7], difference Europe: $-1.8[-2.3,-1.4]$ ). Scaled mass index of all males was lower during the nestling stage than during mating (mating (intercept): 16.3 [15.9, 16.7], difference nestlings: $-0.5[-0.8,-0.3])$.
Males: comparison of CORT between African and Canary Islands stonechats

Considering only males caught during incubation and feeding of young and without STI, post-capture and stress-induced CORT concentrations of Canary Islands males were higher than those of African males (postcapture: Africa (intercept): 2.1 [1.9, 2.3], difference Canary Islands: $1.1[0.7,1.5]$, stress-induced: Africa (intercept): 3.7 [3.6, 3.9], difference Canary Islands: 0.7 $[0.4,1.0]$, Table 4). Scaled mass index did not correlate with CORT (post-capture: slope: $-0.1[-0.3,0.1]$, stressinduced: slope: $-0.1[-0.2,0.1])$. Handling time was positively correlated with post-capture CORT (0.006 $[0.0003,0.01])$.

Table 3 CORT concentrations of male stonechats in relation to breeding region and breeding stage

\begin{tabular}{lll}
\hline & $\begin{array}{l}\text { Post-capture CORT } \\
\text { Estimates and 95\% credible intervals }\end{array}$ & $\begin{array}{l}\text { Stress-induced CORT } \\
\text { Estimates and 95\% credible intervals }\end{array}$ \\
\hline Intercept: Africa, mating stage & $3.7[3.2,4.2]$ & $4.2[3.8,4.6]$ \\
Europe & $-0.6[-1.2,0.1]$ & $\mathbf{0 . 5}[\mathbf{0 . 0 8 , 0 . 9 ]}$ \\
Incubation & $\mathbf{- 0 . 8}[\mathbf{- 1 . 4 , - 0 . 3 ]}$ & $-0.2[-0.4,0.1]$ \\
Young & $\mathbf{- 0 . 8}[\mathbf{- 1 . 2}, \mathbf{- 0 . 3}]$ & $-0.1[-0.4,0.2]$ \\
Europe*incubation & $0.5[-0.2,1.3]$ & $0.4[-0.2,1.0]$ \\
Europe*young & $\mathbf{1 . 0}[\mathbf{0 . 2}, \mathbf{1 . 7}]$ & $0.4[-0.2,1.0]$ \\
Scaled mass index & $-0.09[-0.2,0.04]$ & $-0.03[-0.1,0.07]$ \\
Age yearling & $-0.07[-0.5,0.3]$ & $-0.1[-0.4,0.2]$ \\
STI duration & $\mathbf{0 . 0 0 7}[\mathbf{0 . 0 0 2 , 0 . 0 1 ]}$ & $0.0001[-0.0002,0.0004]$ \\
Time of day & $0.0002[-0.0002,0.0007]$ & \\
Handling time & $0.002[-0.002,0.006]$ &
\end{tabular}

Data shown are estimates and 95\% Bayesian credible intervals of natural log-transformed CORT concentrations. Estimates are relative to the intercept as reference level, which here is the mating stage of African males. The left column shows the post-capture and the right column stress-induced CORT, each with the corresponding Bayesian estimate and its' credible intervals. Estimates of cofactors refer to differences from the intercept estimate. When 0 (zero) is not included in the credible intervals there is an effect of this parameter on the dependent variable (shown in bold). In the case of a significant interaction, the estimated difference of the interaction term is added to the difference of the main effect from the intercept 


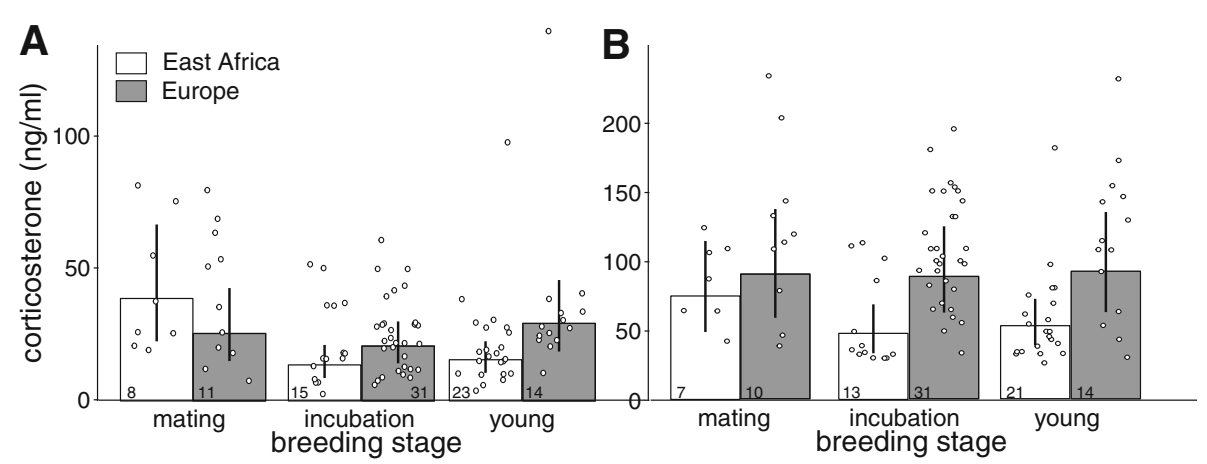

Fig. 2 Effects of breeding region and breeding stage on (a) post-capture and (b) stress-induced CORT concentrations of males. Data show CORT concentrations of African and European male stonechats caught with STI. Bars and error bars represent back-transformed posterior means and their $95 \%$ Bayesian credible intervals

\section{Females: comparison of CORT and body mass index between African and European stonechats}

European females had higher post-capture CORT concentrations than African females (Table 5, Fig. 4a). Post-capture CORT concentrations did not differ with breeding stage and no interaction between breeding region and breeding stage was found (Table 5, Fig.4a). Although females were bled within $3 \mathrm{~min}$, handling time was positively correlated with post-capture CORT (Table 5) and removal of two females that had been bled outside 3 min did not change the effect. Scaled mass index, age, time of day and exposure to STI had no detectable influence on post-capture CORT concentrations (Table 5). European females had slightly higher stress-induced CORT concentrations than African females (Table 5, Fig. 4b). Breeding stage and the interaction between breeding region and breeding stage had no detectable influence on stress- induced CORT concentrations (Table 5, Fig. 4b). Time of day was positively correlated with stress-induced CORT. Scaled mass index and age had no detectable influence on stress-induced CORT concentrations (Table 5).

Stress-induced CORT concentrations correlated positively with baseline CORT concentrations and this relationship did not differ between regions (Africa (intercept): 3.2 [2.7, 3.7], slope all: $0.4[0.3,0.6]$, interaction: 0.04 [-0.3, 0.4], Fig. 3b).

African females had higher scaled mass indices than European females (Africa (intercept): 17.9 [17.2, 18.6], difference Europe: $-0.8[-1.5,-0.1])$. All females had higher scaled mass indices during mating (nest-building and egg-laying) than during all other stages (mating (intercept): 17.9 [17.2, 18.6], difference incubation: -0.9 $[-1.8,-0.05]$, difference nestlings: $-2.1\left[\begin{array}{ll}-2.8, & -1.4\end{array}\right]$, difference fledglings: $-1.8[-2.7,-0.8])$.

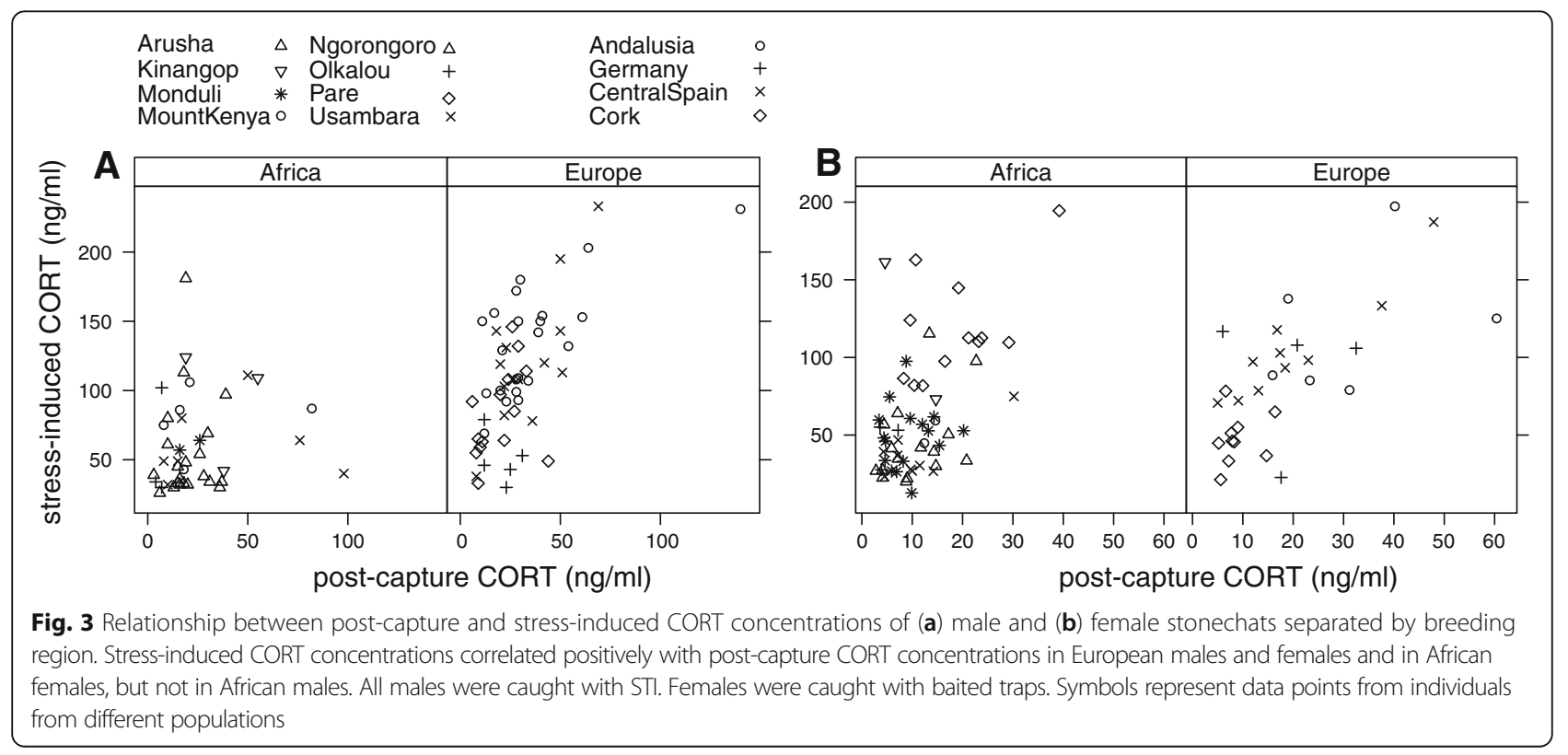


Table 4 Comparison of CORT concentrations of Canary Islands stonechats with those of African and European stonechats

\begin{tabular}{llll}
\hline & Africa & Canary lslands & Europe \\
\hline Males & $\mathrm{ng} / \mathrm{ml}$ & $\mathrm{ng} / \mathrm{ml}$ & $\mathrm{ng} / \mathrm{ml}$ \\
Post-capture CORT & $7.9[6.4,9.8]$ & $23.1[12.4,42.9]$ & $\mathrm{NA}$ \\
Stress-induced CORT & $42.1[35.9,49.1]$ & $84.6[53.8,132.6]$ & $\mathrm{NA}$ \\
Females & & & $16.6[8.0,34.1]$ \\
Post-capture CORT & $9.5[7.9,11.4]$ & $107.2[57.3,200.5]$ & $13.7[7.8,23.9]$ \\
Stress-induced CORT & $51.0[43.4,60.1]$ & $60.8[37.5,98.5]$
\end{tabular}

Data show back-transformed CORT concentrations (mean and 95\% Bayesian credible intervals) of male and female African, Canary Islands and European stonechats during incubation and when feeding young. All individuals were caught without STI. As European males were always caught with STI, they were not included in the comparison with Canary Islands stonechats

Females: comparison of CORT between African, European and Canary Islands stonechats

Post-capture CORT concentrations of females caught during the parental stages (incubation, nestlings, and fledglings) were higher in European and Canary Islands than in African females (Africa (intercept): 2.2 [2.1, 2.4]), difference Europe $(0.4[0.03,0.7])$, difference Canary Islands $(0.6[0.05,1.1]$, Table 4). Canary Islands females had higher stress-induced CORT concentrations than African or European females (Africa (intercept): 3.9 [3.8, 4.1 , difference Europe: 0.2 [-0.1, 0.5], difference Canary Islands: $0.7[0.3,1.2]$, Table 4). Handling time was positively correlated with post-capture CORT (0.006 $[0.0008,0.01])$. Scaled mass index was not correlated with post-capture or stress-induced CORT (post-capture: slope: -0.05 [-0.1, 0.04], stress-induced: slope: $0.001[-0.08,0.09])$.

\section{Males and females: correlations between mates}

Post-capture CORT concentrations of females correlated strongly and positively with post-capture CORT concentrations of their mates, but only when both were caught during the same catching event that involved a simulated territorial intrusion into the pair's territory (intercept: $2.2[1.7,2.7]$, slope (CORT male): $0.1[-0.07,0.3]$, slope (Cort male $\left.{ }^{*} \mathrm{STI}\right): 0.5$ [0.2, 0.9], Fig. 5).

\section{Discussion}

Overall our findings on CORT of male and female stonechats at tropical and temperate sites only partly support predictions based on differences in pace of life. European stonechats have a faster pace of life than African and Canary Islands stonechats. In line with their faster pace of life, higher reproductive investment and parental workload, European females during all breeding stages and European males during parenting had higher post-capture (baseline) CORT concentrations than African females and males. However, during nest-building and egg-laying post-capture CORT concentrations of African males were similar to those of European males.

Table 5 CORT concentrations of female stonechats in relation to breeding region and breeding stage

\begin{tabular}{|c|c|c|}
\hline & Post-capture CORT & Stress-induced CORT \\
\hline & Estimates and $95 \%$ credible intervals & Estimates and 95\% credible intervals \\
\hline $\begin{array}{l}\text { Intercept: } \\
\text { Africa, mating stage }\end{array}$ & $2.2[1.8,2.6]$ & $3.9[3.4,4.3]$ \\
\hline Europe & $0.6[0.08,1.2]$ & $0.7[0.008,1.4]$ \\
\hline Incubation & $-0.3[-0.6,-0.01]$ & $0.04[-0.4,0.5]$ \\
\hline Young & $0.2[-0.2,0.5]$ & $0.2[-0.2,0.6]$ \\
\hline Europe ${ }^{*}$ incubation & $0.005[-0.6,0.6]$ & $-0.4[-1.0,0.2]$ \\
\hline Europe $e^{*}$ oung & $0.03[-0.6,0.7]$ & $-0.5[-1.1,0.1]$ \\
\hline Scaled mass index & $-0.03[-0.1,0.02]$ & $-0.01[-0.06,0.04]$ \\
\hline Age yearling & $0.04[-0.2,0.3]$ & $0.07[-0.1,0.3]$ \\
\hline Time of day & $-0.00002[-0.0004,0.0003]$ & $0.0005[0.0002,0.0008]$ \\
\hline Handling time & $0.007[0.004,0.01]$ & \\
\hline Exposure STI & $0.1[-0.2,0.4]$ & \\
\hline
\end{tabular}



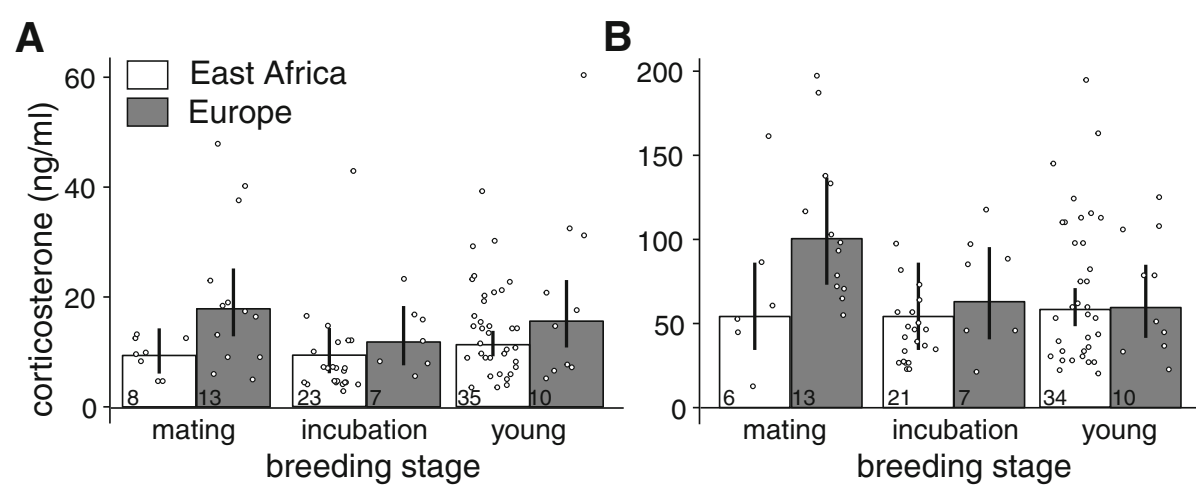

Fig. 4 Effects of breeding region and breeding stage on (a) post-capture and (b) stress-induced CORT concentrations in females. Data show CORT concentrations of African and European female stonechats caught during different breeding stages. European females had overall higher post-capture and stress-induced CORT concentrations than African females. Although African and European birds are presented separately during each breeding stage, an effect of breeding stage or a breeding region*breeding stage interaction were not detectable. Bars and error bars represent back-transformed posterior means and their $95 \%$ Bayesian credible intervals

Furthermore, despite their lower annual reproductive investment and mortality rate, African stonechats had lower stress-induced CORT concentrations than European stonechats. Likewise, we found relatively high postcapture and stress-induced CORT concentrations in slowpaced Canary Islands stonechats. Below we discuss these findings in detail for the contexts of parental workload, territory defence and breeding-stage specific stress responses.

\section{Baseline CORT and parental workload}

Breeding is an energetically demanding life-cycle stage. In female songbirds, basal metabolic rate and energy expenditure are elevated both during egg-laying and when feeding nestlings, and both are also dependent on brood size [81, 82]. Baseline CORT is thought to regulate energetic needs for daily activities [83] and consequently, baseline CORT is upregulated during breeding in many species [22]. This is further supported by studies, in which experimentally elevated CORT increased foraging effort and nestling provisioning rates [27, 29]. Additional support is provided by a brood size manipulation study, in which females of enlarged broods fledged more young and had higher baseline CORT than females of control broods [33]. Furthermore, recent studies in female house wrens (Troglodytes aedon) and European starlings (Sturnus vulgaris) suggest that CORT could also influence fecundity (clutch size and number of clutches) $[26,84]$. The facilitation of fecundity and parental investment by baseline CORT is supported by the results of the current

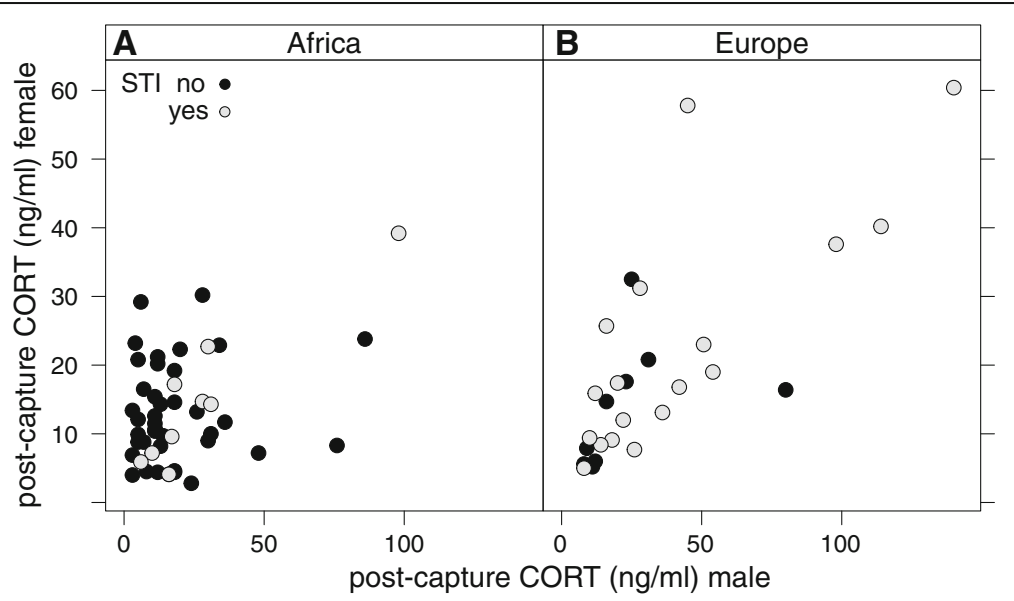

Fig. 5 Correlations between post-capture CORT concentrations of females and their male partners in (a) African and (b) European stonechats. Female post-capture CORT concentrations correlated positively with post-capture CORT concentrations of their mates but only when both mates were exposed to STI 
study where post-capture CORT was found to be higher in European stonechats, which lay more eggs per clutch than African stonechats. All breeding stages combined, African females had lower post-capture CORT than European females. In European males, this contrast was found only when the birds were feeding young. Canary Islands stonechats also had higher post-capture CORT concentrations than African stonechats, although they generally share a slow pace of life. Canary Islands stonechats lay larger clutches during wet (3.7 eggs) than during dry years (2.7 eggs) and are sometimes double-brooded in favourable seasons [56]. For this study, Canary Islands stonechats were caught in a year with good rainfall (2013), which may have resulted in clutches that were larger than those of African stonechats (3.0 eggs). Our results, thus, suggest that the higher energetic costs of laying larger clutches in females and of feeding more nestlings and fledglings in both parents are likely related to higher post-capture CORT concentrations. Similarly, a study on temperate blue tits (Cyanistes caeruleus) found that larger-clutched blue tits breeding on mainland Southern France had higher baseline CORT than small-clutched blue tits breeding on the Island of Corsica [85].

An increased parental work load is commonly associated with physiological costs for birds. For example, increased energy expenditure can have a negative impact on parental fitness through increased production of reactive oxygen species (ROS). ROS can lead to oxidative stress - i.e. oxidative damage to DNA, lipids and proteins [86]. Further, increased parental workload can lead to higher levels of blood parasites and reduced resistance to oxidative stress [87]. Thus, high parental workload may ultimately affect parental survival and should hence be kept low when low mortality allows repeated breeding, and when the value of clutches is low. Our findings of low post-capture CORT in African stonechats supports the general idea of low baseline CORT associated with low reproductive investment. In African stonechats, a long lifespan allows for multiple breeding years, but in each year, the value of a brood may be low because predation on young is high $[7,55]$. We speculate that these life history aspects have selected for overall low baseline CORT levels during the breeding season.

Common garden experiments in stonechats have also shown that tropical stonechats have lower CORT and resting metabolic rates than stonechats from the Northern hemisphere, and that this latter difference is heritable but sensitive to life-history stage $[4,49,50,88,89]$. One study investigated direct relationships between metabolic rates and CORT and found support for associations on the level of population, but not of individuals [50], thus overall supporting the idea of an involvement of CORT in differences of pace of life.

\section{Post-capture CORT and simulated territorial intrusions}

An additional axis of variation in post-capture CORT levels was associated with territorial defense. African males had higher post-capture CORT concentrations when caught after simulated territorial intrusions than when caught with food-baited traps. This confirms similar findings from an earlier study on African male stonechats [31]. In this earlier study, STI was associated with elevated male post-capture CORT concentrations only during the pre-breeding stage. In our study, the effect of STI also appeared to be greatest during early breeding stages, but we did not detect a significant interaction between breeding stage and capture method. CORT has been shown to increase during simulated territorial intrusions in other songbirds [90-94]. This elevation in CORT following STIs is perhaps not surprising as CORT mediates processes that provide the body with readily available energy during challenging situations [83]. Further, CORT can increase context-dependent activity levels [95]. Thus, the high CORT concentrations during STIs reported in the two studies on African stonechats may facilitate a highly active state and the increased energetic needs of defending a territory [31].

Both tropical and temperate stonechats breed seasonally. Species with short breeding seasons breed more synchronously than species with extended breeding seasons, and consequently may face a higher risk of extrapair matings [96]. In particular African males had higher CORT concentrations during mating than during other breeding stages. This peak in CORT concentrations coincides with a peak in testosterone concentrations identified in our twin study on overlapping populations and in other sources. Testosterone peaked during nestbuilding $[18,31,66]$ and the time when male stonechats are most aggressive [18]. In contrast, for European stonechats we could not confirm a similar, matingrelated, peak in post-capture CORT, although seasonal testosterone profiles did not differ between males from different latitudes according to our twin study [18]. Generally, the beginning of the breeding season is a highly demanding and potentially stressful time for birds. Fitness gains by preventing extra-pair copulations of their mates may outweigh the costs of elevated baseline CORT levels for males during this short period of time and similar demands may also affect females. Earlier studies on European stonechats have shown that females are highly responsive to song replay, and that pair interactions may raise CORT concentrations of females in response to territorial intrusions [65, 97]. Our CORT data from paired stonechats support the idea that territorial intrusions affect both mates, as post-capture CORT concentrations of females that were caught during simulated territorial intrusions of their male partners were highly correlated with those of their mates. 


\section{Stress-induced CORT, survival and brood value}

In addition to its role as a metabolic hormone, CORT is one of the major mediators of the stress response in vertebrates. Within minutes of the perception of a stressor, circulating CORT concentrations rise dramatically [98] and facilitate behaviours that promote self-maintenance and survival [21, 42]. Evidence suggests that stressinduced CORT concentrations are modulated with respect to risk to self, as well as with respect to the value of a brood [47, 99]. Because tropical species are longerlived and have a lower reproductive investment than temperate species, it has been proposed that tropical species should be more risk-sensitive and hence their stress response should be higher than that of temperate species [7]. However, although adult mortality is lower in African than in European stonechats [52, 54], in the current study, African stonechats had lower stressinduced CORT concentrations than European stonechats. These findings correspond with common garden studies of four of the stonechat populations studied here, which also found that stress-induced CORT concentrations were lowest in African stonechats [50]. A possible reason is that although fecundity (clutch size and number of broods) is usually higher in temperate environments, investment into individual offspring - both during the nestling stage and post-fledging - may be higher in tropical environments leading to higher quality offspring in tropical birds [100, 101]. For example, African stonechats take care of their fledglings for at least six weeks, while European stonechats overlap clutches and initiate a second clutch when fledglings are only two weeks old $[55,102]$. Field studies suggest that predators are a main reason for this extended parental care and possibly for single-broodedness in African stonechats [55, 103], where especially males actively guard their fledglings against predators. A comparative study showed that males in territories where shrikes - the main predators of fledglings - were present had a lower body condition and elevated baseline CORT compared to males in territories without shrikes [55]. High stressinduced CORT can induce parents to leave their brood [104]. Because of their relatively short breeding season, tropical stonechats may not be able to re-nest when their brood fails during the fledgling stage. Thus, in our tropical region, where predators on fledglings are plenty, the prolonged parental care provided by stonechats may be critical for fledged young to reach independence, and hence, be facilitated by a dampened CORT stress response. Supporting this idea further, stress-induced CORT concentrations of male African stonechats decreased with breeding stage and were lower when they had fledglings than during mating. A dampened stress-response during the nestling/fledgling stage may be a more general pattern in challenging environments where re-nesting possibilities are scarce. For example, in Arctic-breeding sparrows males had a lower CORT response to handling stress when feeding nestlings than before eggs hatched [105]. In Arctic regions where storms and harsh weather occur frequently during the breeding season, a dampened stress response may prevent parents from too readily jeopardizing their brood without possibilities to re-nest [106].

In accordance with their high annual survival, male Canary Islands stonechats had higher stress-induced CORT than African and European stonechats. As common for many island species, nest-failure due to predation on young is lower in Canary Islands than in African and European stonechats. Nest failure was especially low before the introduction of predatory mammals $[107,108]$, which now are the main causes of nest failure in the Canary Islands stonechat (29\% of nests failed; $67 \%$ of these predation events were due to feral cats during 2000-2003, [56, 109]). Thus, introduced predatory species may exert a selective pressure that may dampen the CORT stress-response in the future. Together with captive studies from stonechats [50] and swamp sparrow subspecies (Melospiza sp.) [110] our data suggest that the CORT stress response has a genetic basis and responds to selection pressures associated with environmental conditions and alternative life histories.

\section{Conclusions}

Our data support the view that baseline CORT concentrations facilitate energetically demanding activities in males and females and reflect investment into reproduction. Reduced parental workload because of small clutches and consequently lower concentrations of circulating CORT may, thus, contribute to a slow pace of life in tropical species. However, our data call for a refinement of this classical conclusion of tropicaltemperate comparisons: the patterns can differ or even be reversed during specific life-cycle stages. In species with short breeding seasons a potentially high risk of extra-pair copulations may favour high baseline CORT concentrations at the beginning of the breeding season in particular in tropical males. Likewise, contrasting with the hypothesis that species with high annual survival and a slow pace of life should be more risk-sensitive, tropical stonechats had lower stress-induced CORT concentrations than temperate stonechats during the breeding season. A dampened stress response during parental stages may increase survival probabilities of young in predator-rich tropical environments. Overall, our data further support a mediating role of baseline CORT relative to reproductive effort. In contrast, stress - induced CORT did not follow the predictions from life history theory, nor classical tropicaltemperate patterns. To resolve these uncertainties, 
more studies are needed that reveal which environmental factors have shaped the CORT stress response and its consequences for avian fitness.

\section{Additional files}

Additional file 1: Table S1. Geographical and life history information of populations studied. (DOCX $18 \mathrm{~kb}$ )

Additional file 2: Datasets analyzed during the current study. (XLSX $113 \mathrm{~kb}$ )

\section{Abbreviations}

SMI: Scaled mass index; STI: Simulated territorial intrusion

\section{Acknowledgments}

We want to thank Lynne Flemming for her support and advice on the EIA, John O'Halloran for organizing the fieldwork in Ireland, and Guillermo López, Musa Makomba, Isaac (Monduli), Julius (Pare), Jack Kiru and Ann Gathitu for help with fieldwork and two anonymous reviewers for valuable comments on previous versions of the manuscript. We also thank the National Museums of Kenya (NMK) and the Tanzania Wildlife Research Institute (TAWIRI) for providing support for fieldwork.

\section{Availability of data and materials}

The datasets analyzed during the current study are available as Additional file 2.

\section{Ethics approval}

All experimental procedures were approved by the governmental authorities of the respective countries (Germany: Regional Government of North Rhine Westphalia and Vogelwarte Helgoland License No. 0147; Ireland: License No. C092/2013; Kenya: National Commission for Science, Technology and Innovation (NACOSTI); Spain: Regional Governments of Junta de Castilla y León (EP-CYL-33-2013), Andalucía (35-36/13) and the Canary Islands (2012/ 0710); Tanzania: Tanzania Wildlife Research Institute (TAWIRI) and Tanzania Commission for Science and Technology (COSTECH)).

\section{Funding}

This work was supported by the Alexander von Humboldt Foundation (BA), the British Society for Neuroendocrinolgy (BA, NE), and the German Science foundation (DFG, research grant to BH grant HE3488/5-1).

\section{Authors' contributions}

$\mathrm{BA}, \mathrm{KGM}$ and $\mathrm{BH}$ conceived of and designed the project. BA, KGM, JCI, PS collected the data. BA analysed the data. BA wrote the manuscript with essential input from NE and BH. BA designed the figures. All authors read, edited, and approved the final manuscript.

\section{Competing interests}

The authors declare that they have no competing interests.

\section{Consent for publication}

Not applicable.

\section{Publisher's Note}

Springer Nature remains neutral with regard to jurisdictional claims in published maps and institutional affiliations.

\section{Author details}

'Institute of Biodiversity, Animal Health and Comparative Medicine, University of Glasgow, Glasgow, Scotland G12 8QQ, UK. ${ }^{2}$ Terrestrial Ecology Research Group, Department of Ecology and Ecosystemmanagement, Technische Universität München, School of Life Sciences Weihenstephan, D-85354 Freising, Germany. ${ }^{3}$ Department of Migration and Immunoecology, Max-Planck-Institut für Ornithologie, D-78315 Radolfzell, Germany. ${ }^{4}$ Research Unit of Biodiversity (UO-CSIC-PA), Oviedo University, Campus of Mieres, 33600 Mieres, Spain. ${ }^{5}$ School of Biological, Earth and Environmental Sciences, University College Cork, Cork T12 YN60, Ireland.
Received: 3 January 2017 Accepted: 8 May 2017

Published online: 22 May 2017

\section{References}

1. Promislow DEL, Harvey PH. Living fast and dying young: A comparative analysis of life-history variation among mammals. J. Zool. 1990;220:417-37.

2. Jetz W, Sekercioglu CH, Böhning-Gaese K. The worldwide variation in avian clutch size across species and space. PLoS Biol. 2008;6:-e303.

3. Wiersma P, Muñoz-Garcia A, Walker A, Williams JB. Tropical birds have a slow pace of life. Proc. Natl. Acad. Sci. 2007;104:9340-5.

4. Tieleman BI, Versteegh MA, Fries A, Helm B, Dingemanse NJ, Gibbs HL, Williams JB. Genetic modulation of energy metabolism in birds through mitochondrial function. Proc. R. Soc. Lond. B Biol. Sci. 2009:276:1685-93.

5. Møller AP. Senescence in relation to latitude and migration in birds. J. Evol. Biol. 2007;20:750-7.

6. Peach WJ, Hanmer DB, Oatley TB. Do southern African songbirds live longer than their European counterparts? Oikos. 2001:93:235-49.

7. Ricklefs RE, Wikelski M. The physiology/life-history nexus. Trends Ecol. Evol. 2002:17:462-8.

8. Nur N. The Consequences of brood size for breeding blue tits. III. Measuring the cost of reproduction: Survival, future fecundity, and differential dispersal. Evolution. 1988:42:351-62.

9. Daan S, Deerenberg C, Dijkstra C. Increased daily work precipitates natural death in the kestrel. J. Anim. Ecol. 1996:65:539-44.

10. Dijkstra C, Bult A, Bijlsma S, Daan S, Meijer T, Zijlstra M. Brood size manipulations in the kestrel (Falco tinnunculus): Effects on offspring and parent survival. J. Anim. Ecol. 1990;59:269-85.

11. Jarvisto PE, Calhim S, Schuett W, Velmala W, Laaksonen T. Sex-dependent responses to increased parental effort in the pied flycatcher. Behav. Ecol. Sociobiol. 2016;70:157-69.

12. Hodges CJ, Bowers EK, Thompson CF, Sakaluk SK. Cascading costs of reproduction in female house wrens induced to lay larger clutches. J. Evol. Biol. 2015:28:1383-93.

13. Stearns SC. The evolution of life histories. Oxford: Oxford University Press; 1992.

14. Zera AJ, Harshman LG. The physiology of life history trade-offs in animals. Annu. Rev. Ecol. Syst. 2001;32:95-126.

15. Ketterson ED, Nolan JV. Hormones and life histories: an integrative approach. Am. Nat. 1992;140:S33-62.

16. Hau M, Wingfield JC. Hormonally-regulated trade-offs: Evolutionary variability and phenotypic plasticity in testosterone signaling pathways. In: Flatt T, Heyland A, editors. Mechanisms of life history evolution: The genetics and physiology of life history traits and trade-offs. Oxford: Oxford University Press; 2011.

17. Hau M, Ricklefs RE, Wikelski M, Lee KA, and Brawn JD. Corticosterone, testosterone and life-history strategies of birds. Proc R Soc Lond B Biol Sci. 2010;277:3203-212.

18. Apfelbeck B, Mortega KG, Flinks H, Illera JC, Helm B. Testosterone, territorial response, and song in seasonally breeding tropical and temperate stonechats. BMC Evol. Biol. 2017:17:101.

19. Landys MM, Ramenofsky M, Wingfield JC. Actions of glucocorticoids at a seasonal baseline as compared to stress-related levels in the regulation of periodic life processes. Gen. Comp. Endocrinol. 2006;148:132-49.

20. Romero LM, Dickens MJ, Cyr NE. The reactive scope model - A new mode integrating homeostasis, allostasis, and stress. Horm. Behav. 2009;55:375-89.

21. Wingfield JC, Maney DL, Breuner CW, Jacobs JD, Lynn S, Ramenofsky M, Richardson RD. Ecological bases of hormone-behavior interactions: the "emergency life history stage". Am. Zool. 1998;38:191-206.

22. Romero LM. Seasonal changes in plasma glucocorticoid concentrations in free-living vertebrates. Gen. Comp. Endocrinol. 2002;128:1-24.

23. Wada H, Moore IT, Breuner CW, Wingfield JC. Stress responses in tropical sparrows: comparing tropical and temperate Zonotrichia. Physiol. Biochem. Zool. 2006;79:784-92.

24. Buttemer WA, Addison BA, Astheimer LB. Lack of seasonal and moult-related stress modulation in an opportunistically breeding bird: The white-plumed honeyeater (Lichenostomus penicillatus). Horm. Behav. 2015;76:34-40.

25. Deviche P, Valle S, Gao S, Davies S, Bittner S, Carpentier E. The seasonal glucocorticoid response of male Rufous-winged Sparrows to acute stress correlates with changes in plasma uric acid, but neither glucose nor testosterone. Gen. Comp. Endocrinol. 2016;235:78-88.

26. Love $\mathrm{OP}$, Madliger $\mathrm{CL}$, Bourgeon S, Semeniuk CAD, Williams TD. Evidence for baseline glucocorticoids as mediators of reproductive investment in a wild bird. Gen. Comp. Endocrinol. 2014;199:65-9. 
27. Ouyang JQ, Muturi M, Quetting M, Hau M. Small increases in corticosterone before the breeding season increase parental investment but not fitness in a wild passerine bird. Horm. Behav. 2013;63:776-81.

28. Ouyang J, Sharp P, Quetting M, Hau M. Endocrine phenotype, reproductive success and survival in the great tit, Parus major. J Evol Biol. 2013;26:1988-98.

29. Crossin GT, Trathan PN, Phillips RA, Gorman KB, Dawson A, and Sakamoto $\mathrm{KQ}$. Corticosterone predicts foraging behavior and parental care in macaroni penguins. Am Nat. 2012;180:E31-E41.

30. Riechert J, Chastel O, Becker PH. Regulation of breeding behavior: Do energy-demanding periods induce a change in prolactin or corticosterone baseline levels in the common tern (Sterna hirundo)? Physiol. Biochem. Zool. 2014;87:420-31.

31. Goymann W, Geue D, Schwabl I, Flinks H, Schmidl D, Schwabl H, Gwinner E. Testosterone and corticosterone during the breeding cycle of equatorial and European stonechats (Saxicola torquata axillaris and S. t. rubicola). Horm. Behav. 2006;50:779-85

32. Goymann W, Trappschuh M, and Urasa F. Corticosterone concentrations reflect parental expenditure in contrasting mating systems of two coucal species. Fron Ecol Evol. 2017:5:1-11.

33. Bonier F, Moore IT, Robertson RJ. The stress of parenthood? Increased glucocorticoids in birds with experimentally enlarged broods. Biol. Lett. 2011;7:944-6.

34. Bonier F, Moore IT, Martin PR, Robertson RJ. The relationship between fitness and baseline glucocorticoids in a passerine bird. Gen. Comp. Endocrinol. 2009;163:208-13.

35. Ouyang JQ, Sharp PJ, Dawson A, Quetting M, Hau M. Hormone levels predict individual differences in reproductive success in a passerine bird. Proc R Soc Biol Sci. 2011;278:2537-45.

36. Riechert J, Becker $\mathrm{PH}$, Chastel O. Predicting reproductive success from hormone concentrations in the common tern (Sterna hirundo) while considering food abundance. Oecologia. 2014;176:715-27.

37. Crossin GT, Phillips RA, Lattin CR, Romero LM, Williams TD. Corticosterone mediated costs of reproduction link current to future breeding. Gen. Comp. Endocrinol. 2013;193:112-20.

38. Koren L, Nakagawa S, Burke T, Soma KK, Wynne-Edwards KE, Geffen E. Nonbreeding feather concentrations of testosterone, corticosterone and cortisol are associated with subsequent survival in wild house sparrows. Proc. R. Soc. Lond. B Biol. Sci. 2012;279:1560-6.

39. Breuner CW, Patterson SH, Hahn TP. In search of relationships between the acute adrenocortical response and fitness. Gen. Comp. Endocrinol. 2008;157:288-95.

40. Hau M, Casagrande S, Ouyang JQ, and Baugh AT, Glucocorticoid-mediated phenotypes in vertebrates: multilevel variation and evolution., in Advances in the Study of Behavior., M. Naguib, et al., Editors. Cambridge: Academic Press; 2016. p. 41-115.

41. Angelier F, Clément-Chastel C, Welcker J, Gabrielsen GW, Chastel O. How does corticosterone affect parental behaviour and reproductive success? A study of prolactin in black-legged kittiwakes. Funct. Ecol. 2009;23:784-93.

42. Breuner CW, Hahn TP. Integrating stress physiology, environmental change, and behavior in free-living sparrows. Horm. Behav. 2003;43:115-23.

43. Silverin B. Corticosterone-binding proteins and behavioral effects of high plasma levels of corticosterone during the breeding period in the pied flycatcher. Gen. Comp. Endocrinol. 1986;64:67-74.

44. Bonier F, Martin PR, Moore IT, and Wingfield JC. Do baseline glucocorticoids predict fitness? Trends Ecol Evol. 2009;24:634-42.

45. Cornelius JM, Breuner CW, Hahn TP. Coping with the extremes: stress physiology varies between winter and summer in breeding opportunists. Biol. Lett. 2012;8:312-5

46. Angelier F, Holberton RL, Marra PP. Does stress response predict return rate in a migratory bird species? A study of American redstarts and their nonbreeding habitat. Proc. R. Soc. Lond. B Biol. Sci. 2009;276:3545-51.

47. Bókony V, Lendvai AZ, Liker A, Angelier F, Wingfield JC, and Chastel $O$. Stress response and the value of reproduction: are birds prudent parents? Am Nat. 2009;173:589-98.

48. Urquhart ED. Stonechats. London: Christopher Helm; 2002.

49. Klaassen M. Moult and basal metabolic costs in males of two subspecies of stonechats: the European Saxicola torquata rubicula and the East African S. $t$. axillaris. Oecologia. 1995;104:424-32.

50. Versteegh MA, Schwabl I, Jaquier S, Tieleman BI. Do immunological, endocrine and metabolic traits fall on a single Pace-of-Life axis? Covariation and constraints among physiological systems. J. Evol. Biol. 2012;25:1864-76.
51. Gwinner E, König S, Haley CS. Genetic and environmental factors influencing clutch size in equatorial and temperate zone stonechats (Saxicola torquata axillaris and S. T. rubicola): an experimental study. Auk. 1995;112:748-55.

52. Scheuerlein A. Control of reproduction in a tropical bird, the stonechat (Saxicola torquata axillaris). Shaker Verlag: Aachen; 2000.

53. Flinks H, Pfeifer F. Zur Verbreitung und Populationsentwicklung des Schwarzkehlchens (Saxicola torquata) in Nordrhein-Westfalen. Vogelwelt. 1984;105:41-51.

54. Flinks $H$, Helm B, Rothery P. Plasticity of moult and breeding schedules in migratory European Stonechats (Saxicola rubicola). Ibis. 2008;150:687-97.

55. Scheuerlein A, Van't Hof T, Gwinner E. Predators as stressors? Physiological and reproductive consequences of predation risk in tropical stonechats (Saxicola torquata axillaris). Proc. R. Soc. Lond. B Biol. Sci. 2001;268:1575-82.

56. Illera JC, Díaz M. Reproduction in an endemic bird of a semiarid island: a food-mediated process. J. Avian Biol. 2006:37:447-56.

57. Illera JC, Díaz M. Site fidelity in the Canary Islands stonechat, Saxicola dacotiae, in relation to spatial and temporal patterns of habitat suitability. Acta Oecol. 2008;34:1-8.

58. Scheuerlein A and Gwinner E. Proximate and ultimate aspects of photoperiodic sensitivity in equatorial stonechats, Saxicola torquata axillaris. In N. J. Adams, \& R. H. Slotow (Eds.), Proceedings of the 22nd International Ornithological Congress 1999. Johannesburg: Birdlife South Africa. 1999;1756-766.

59. Dittami JP, Gwinner E. Annual cycles in the African stonechat Saxicola torquata axillaris and their relationship to environmental factors. J. Zool. 1985;207:357-70.

60. Flinks H. Die Altersbestimmung des Schwarzkehlchens Saxicola torquata rubicola an Gefiedermerkmalen. Limicola. 1994;8:28-37.

61. Illera JC, Atienza JC. Determinación del sexo y edad en la Tarabilla Canaria Saxicola Dacotiae mediante el estudio de la muda. Ardeola. 2002:49:273-81.

62. Gwinner E, Roedl T, Schwabl H. Pair territoriality of wintering stonechats : behaviour, function and hormones. Behav. Ecol. Sociobiol. 1994:34:321-7.

63. Canoine V, Gwinner E. Seasonal differences in the hormonal control of territorial aggression in free-living European stonechats. Horm. Behav. 2002;41:1-8.

64. Marasco V, Fusani L, Dessì-Fulgheri F, Canoine V. Non-migratory stonechats show seasonal changes in the hormonal regulation of non-seasonal territorial aggression. Horm. Behav. 2011;60:414-9.

65. Mortega KG, Flinks H, and Helm B. Behavioural response of a migratory songbird to geographic variation in song and morphology. Front Zool. 2014;11:1-13.

66. Schwabl H, Flinks H, Gwinner E. Testosterone, reproductive stage, and territorial behavior of male and female European stonechats Saxicola torquata. Horm. Behav. 2005;47:503-12.

67. Apfelbeck B, Flinks H, Goymann W. Territorial aggression does not feed back on testosterone in a multiple-brooded songbird species with breeding and nonbreeding season territoriality, the European stonechat. Horm. Behav. 2017;87:89-95.

68. Romero LM, Reed JM. Collecting baseline corticosterone samples in the field: is under 3 min good enough? Comp Biochem Physiol A Mol Integr Physiol. 2005;140:73-9.

69. Newman AEM, Pradhan DS, Soma KK. Dehydroepiandrosterone and corticosterone are regulated by season and acute stress in a wild songbird: jugular versus brachial plasma. Endocrinology. 2008:149:2537-45.

70. Goymann W, Schwabl I, Trappschuh M, Hau M. Use of ethanol for preserving steroid and indoleamine hormones in bird plasma. Gen. Comp. Endocrinol. 2007;150:191-5.

71. Rosvall KA, Reichard DG, Ferguson SM, Whittaker DJ, Ketterson ED. Robust behavioral effects of song playback in the absence of testosterone or corticosterone release. Horm. Behav. 2012;62:418-25.

72. RCoreTeam, R: A Language and Environment for Statistical Computing 2016 , R Foundation for Statistical Computing: Vienna, Austria.

73. Gelman A and Su Y-S, arm: data analysis using regression and multilevel/ hierarchical models. R package version 1.8-6., 2015.

74. Plummer M. JAGS : a program for analysis of Bayesian graphical models using Gibbs Sampling. In: Hornik K, Leisch F, Zeileis A, editors. Proceedings of the 3rd International Workshop on Distributed Statistical Computing. Vienna: Technische Universität Wien; 2003.

75. Denwood MJ. runjags: An R package providing interface utilities, parallel computing methods and additional distributions for MCMC models in JAGS. J. Stat. Softw. 2016;71:1-25.

76. Peig J, Green AJ. The paradigm of body condition: a critical reappraisal of current methods based on mass and length. Funct. Ecol. 2010;24:1323-32.

77. Bolker BM, Brooks ME, Clark CJ, Geange SW, Poulsen JR, Stevens MHH, White JSS. Generalized linear mixed models: a practical guide for ecology and evolution. Trends Ecol. Evol. 2009;24:127-35. 
78. Korner-Nievergelt F, Roth T, Von Felten S, Guélat J. Bayesian Data Analysis in Ecology Using Linear Models with R, BUGS, and Stan. Amsterdam: Academic Press; 2015.

79. Brooks SP, Gelman A. General methods for monitoring convergence of iterative simulations. J. Comput. Graph. Stat. 1997;7:434-55.

80. Held L, Sabanés BD. Applied statistical inference. Berlin-Heidelberg: Springer; 2014.

81. Nilsson JA. Metabolic consequences of hard work. Proc. R. Soc. Lond. B Biol. Sci. 2002;269:1735-9.

82. Williams TD. Mechanisms underlying the costs of egg production. Bioscience. 2005;55:39-48.

83. Landys MM, Ramenofsky M, and Wingfield JC. Actions of glucocorticoids at a seasonal baseline as compared to stress-related levels in the regulation of periodic life processes. Gen Comp Endocrinol. 2006;148:132-49.

84. Bowers EK, Bowden RM, Thompson CF, Sakaluk SK. Elevated corticosterone during egg production elicits increased maternal investment and promotes nestling growth in a wild songbird. Horm. Behav. 2016;83:6-13.

85. Müller C, Jenni-Eiermann S, Blondel J, Perret P, Caro SP, Lambrechts MM, Jenni L. Circulating corticosterone levels in breeding blue tits, Parus caeruleus, differ between island and mainland populations and between habitats. Gen. Comp. Endocrinol. 2007;154:128-36.

86. Fletcher QE, Selman C, Boutin S, McAdam AG, Woods SB, Seo AY, Leeuwenburgh C, Speakman JR, Humphries MM. Oxidative damage increases with reproductive energy expenditure and is reduced by foodsupplementation. Evolution. 2013;67:1527-36.

87. Christe P, Glaizot O, Strepparava N, Devevey G, Fumagalli L. Twofold cost of reproduction: an increase in parental effort leads to higher malarial parasitaemia and to a decrease in resistance to oxidative stress. Proc. R. Soc. Lond. B Biol. Sci. 2012;279:1142-9.

88. Versteegh MA, Helm B, Gwinner E, Tieleman BI. Annual cycles of metabolic rate are genetically determined but can be shifted by phenotypic flexibility. J. Exp. Biol. 2012;215:3459-66.

89. Wikelski M, Spinney L, Schelsky W, Scheuerlein A, Gwinner E. Slow pace of life in tropical sedentary birds: a common-garden experiment on four stonechat populations from different latitudes. Proc. R. Soc. Lond. B Biol. Sci. 2003;270:2383-8.

90. Charlier TD, Underhill C, Hammond GL, Soma KK. Effects of aggressive encounters on plasma corticosteroid-binding globulin and its ligands in white-crowned sparrows. Horm. Behav. 2009:56:339-47.

91. Deviche P, Beouche-Helias B, Davies S, Gao S, Lane S, Valle S. Regulation of plasma testosterone, corticosterone, and metabolites in response to stress, reproductive stage, and social challenges in a desert male songbird. Gen. Comp. Endocrinol. 2014;203:120-31.

92. Landys MM, Goymann W, Raess M, Slagsvold T. Hormonal responses to malemale social challenge in the blue tit, Cyanistes caeruleus: single-broodedness as an explanatory variable. Physiol. Biochem. Zool. 2007;80:228-40.

93. Landys MM, Goymann W, Schwabl I, Trapschuh M, Slagsvold T. Impact of season and social challenge on testosterone and corticosterone levels in a year-round territorial bird. Horm. Behav. 2010;58:317-25.

94. Gill SA, Costa LM, Hau M. Males of a single-brooded tropical bird species do not show increases in testosterone during social challenges. Horm. Behav. 2008;54:115-24.

95. Astheimer LB, Buttemer WA, and Wingfield JC. Interactions of corticosterone with feeding, activity and metabolism in passerine birds. Ornis Scand. 1992;23:355-65

96. Stutchbury BJ, Morton ES. The effect of breeding synchrony on extra-pair mating systems in songbirds. Behaviour. 1995;132:675-90.

97. Canoine V, Gwinner E. The hormonal response of female European Stonechats to a territorial intrusion: the role of the male partner. Horm. Behav. 2005;47:563-8.

98. Jones BC, Smith AD, Bebus SE, Schoech SJ. Two seconds is all it takes: European starlings (Sturnus vulgaris) increase levels of circulating glucocorticoids after witnessing a brief raptor attack. Horm. Behav. 2016;78:72

99. Schmid B, Tam-Dafond L, Jenni-Eiermann S, Arlettaz R, Schaub M, Jenni L. Modulation of the adrenocortical response to acute stress with respect to brood value, reproductive success and survival in the Eurasian hoopoe. Oecologia. 2013;173:33-44

100. Martin TE. Age-related mortality explains life history strategies of tropical and temperate songbirds. Science. 2015;349:966-70.

101. Russell EM, Yom-Tov Y, Geffen E. Extended parental care and delayed dispersal: northern, tropical, and southern passerines compared. Behav. Ecol. 2004;15:831-8.
102. Flinks H, Pfeifer F. Brutzeit, Gelegegröße und Bruterfolg beim Schwarzkehlchen (Saxicola torquata). Charadrius. 1987:23:128-40.

103. Koenig S, Gwinner E. Frequency and timing of successive broods in captive African and European stonechats Saxicola torquata axillaris and S. t. rubicola. J. Avian Biol. 1995:26:247-54.

104. Ouyang JQ, Quetting M, Hau M. Corticosterone and brood abandonment in a passerine bird. Anim. Behav. 2012;84:261-8.

105. Holberton RL, Wingfield JC. Modulating the corticosterone stress response: a mechanism for balancing individual risk and reproductive success in arcticbreeding sparrows? Auk. 2003;120:1140-50.

106. Wingfield JC, Hunt KE. Arctic spring: hormone-behavior interactions in a severe environment. Comp Biochem Physiol B Biochem Mol Biol. 2002;132:275-86.

107. Whittaker RJ, Fernandez-Palacios JM. Island Biogeography. Ecology, Evolution and Conservation. Oxford: Oxford University Press; 1998.

108. Illera JC, Spurgin LG, Rodriguez-Exposito E, Nogales M, Rando JC. What are we learning about speciation and extinction from the Canary Islands? Ardeola. 2016:63:15-33.

109. Nogales M, Martin A, Tershy BR, Donlan CJ, Witch D, Puerta N, Wood B, Alonso J. A review of feral cat eradication on islands. Conserv. Biol. 2004;18:310-9.

110. Angelier F, Ballentine B, Holberton RL, Marra PP, Greenberg R. What drives variation in the corticosterone stress response between subspecies? A common garden experiment of swamp sparrows (Melospiza georgiana). J. Evol. Biol. 2011;24:1274-83.

\section{Submit your next manuscript to BioMed Central and we will help you at every step:}

- We accept pre-submission inquiries

- Our selector tool helps you to find the most relevant journal

- We provide round the clock customer support

- Convenient online submission

- Thorough peer review

- Inclusion in PubMed and all major indexing services

- Maximum visibility for your research

Submit your manuscript at www.biomedcentral.com/submit
) Biomed Central 